\title{
Development of a Checklist of Safe Discharge Practices for Hospital Patients
}

\author{
Christine Soong, MD ${ }^{1 \star}$, Stacey Daub, MBA², Joseph Lee, MD, MCISc${ }^{3}$, Cynthia Majewski ${ }^{4}$, Emily Musing, RPh, BScPhm, MHSc ${ }^{5}$, \\ Peter Nord, MD6, Roy Wyman, MD, G. Ross Baker, PhD, Nick Zacharopoulos, BA, BEd8, Chaim M. Bell, MD, PhD1
}

${ }^{1}$ Division of General Internal Medicine, University of Toronto, Toronto, Ontario, Canada; ${ }^{2}$ Toronto Central Community Care Access Centre, Toronto, Ontario, Canada; ${ }^{3}$ Department of Family Medicine, McMaster University, Hamilton, Ontario, Canada; ${ }^{4}$ Quality Healthcare Network, Toronto, Ontario, Canada; ${ }^{5}$ Faculty of Pharmacy, University of Toronto, Toronto, Ontario, Canada; ${ }^{6}$ Department of Family and Community Medicine, University of Toronto, Toronto, Ontario, Canada; 'Institute of Health Policy, Management and Evaluation, University of Toronto, Toronto, Ontario, Canada; ${ }^{8}$ Ontario Public Service, Toronto, Ontario, Canada.

BACKGROUND: Discharge from hospital can be a vulnerable period for patients. Multifaceted "discharge bundles" facilitate care transitions and possibly decrease adverse outcomes. We describe a structured approach to discharge planning, starting from admission and proceeding through discharge, using a standardized checklist of tasks to be performed for each hospitalization day.

OBJECTIVE: To create an evidence-based checklist of safe discharge practices for hospital patients.

METHODS: In the province of Ontario, the Ministry of Health and Long-Term Care convened a panel of expert members from multiple disciplines and across several healthcare sectors. The panel conducted a systematic search of the literature and used a structured approach to review evidence-based practices that ensure efficient, effective, safe, and patient-centered care transitions. A discharge-checklist tool was created to facilitate safe discharge from hospital.

RESULTS: The final checklist describes the processes necessary for a safe and optimal discharge and recommended timeline of when to complete each step, starting from the first day of admission. The checklist domains include (1) indication for hospitalization, (2) primary care, (3) medication safety, (4) follow-up plans, (5) home-care referral, (6) communication with outpatient providers, and (7) patient education.

CONCLUSIONS: The Checklist of Safe Discharge Practices for Hospital Patients summarizes the sequence of events that need to be completed throughout a typical hospitalization. Standardizing discharge planning and initiating processes early on in a patient's hospital stay may ensure a safe transition home. Journal of Hospital Medicine 2013;8:444449. (c) 2013 Society of Hospital Medicine.
The transition from hospital to home can expose patients to adverse events during the postdischarge period. $^{1,2}$ Deficits in communication at hospital discharge are common, ${ }^{3}$ and accurate information on important hospital events is often inadequately transmitted to outpatient providers, which may adversely affect patient outcomes. ${ }^{4-6}$ "Discharge bundles" (multifaceted interventions including patient education, structured discharge planning, medication reconciliation, and follow-up visits or phone calls) are strategies that provide support to patients returning home and facilitate transfer of information to primary-care providers (PCPs). ${ }^{7-9}$ These interventions collectively may improve patient satisfaction and possibly reduce rehospitalization. ${ }^{10}$

Beginning in 2012, the Centers for Medicare and Medicaid Services will be reducing payments to

*Address for correspondence and reprint requests: Christine Soong MD, Division of General Internal Medicine, Mount Sinai Hospital, 600 University Ave, Room 428, Toronto, ON M5G 1X5 Canada; Telephone: 416586-4800; Fax: 647-776-3148; E-mail: csoong@mtsinai.on.ca

Additional Supporting Information may be found in the online version of this article.

Received: November 26, 2012; Revised: January 29, 2013; Accepted: February 10, 2013

2013 Society of Hospital Medicine DOI 10.1002/jhm.2032

Published online in Wiley Online Library (Wileyonlinelibrary.com). facilities with high rates of readmissions. ${ }^{11}$ Thus, improving care transitions and thereby reducing avoidable readmissions are now priorities in many jurisdictions in the United States. There is a similar focus on readmission rates in the province of Ontario. ${ }^{12}$ The Ontario Ministry of Health and LongTerm Care convened an expert advisory panel with a mandate to provide guidance on evidence-based practices that ensure efficient, effective, safe, and patientcentered care transitions. ${ }^{13}$ The objective of this study is to describe a structured panel approach to safe discharge practices, including a checklist of a recommended sequence of steps that can be followed throughout the hospital stay. This tool can aid efforts to optimize patient discharge from the hospital and improve outcomes.

\section{METHODS}

\section{Literature Review}

The research team reviewed the literature to determine the nature and format of the core information to be contained in a discharge checklist for hospitalized patients. We searched Medline (through January 2011) for relevant articles. We used combined Medical Subject Headings and keywords using "patient discharge," "transition," and "medication reconciliation." Bibliographies of all relevant articles were 


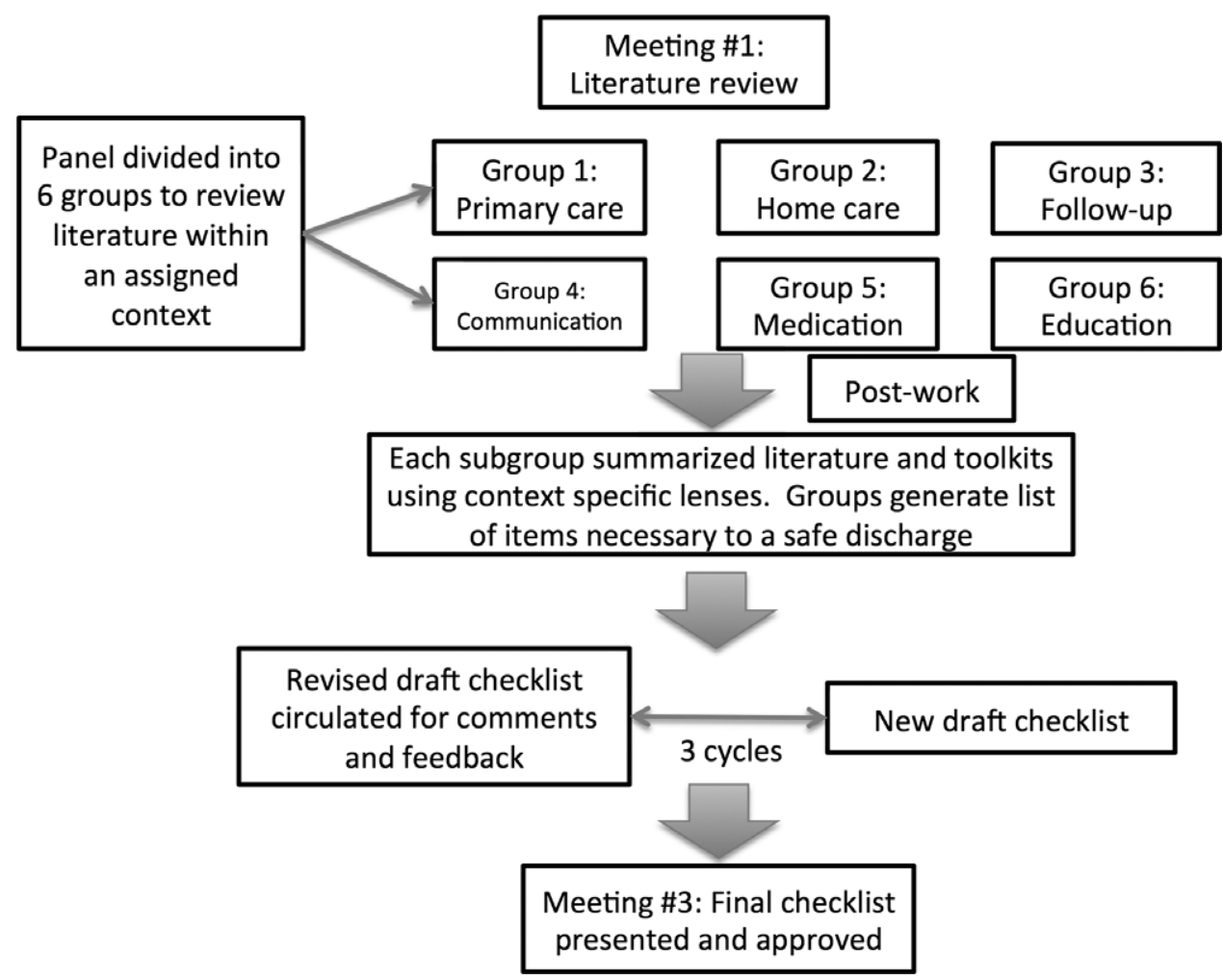

FIG. 1. The checklist-development process.

reviewed to identify additional studies. In addition, we conducted a focused study of select resources, such as the systematic review examining interventions to reduce rehospitalization by Hansen and colleagues, ${ }^{10}$ the Transitional Care Initiative for heart failure patients ${ }^{14}$ the Care Transitions Intervention, ${ }^{15}$ Project RED (Re-Engineered Hospital Discharge), ${ }^{7}$ Project BOOST (Better Outcomes by Optimizing Safe Transitions), ${ }^{16}$ and The King's Fund report on avoiding hospital admissions. ${ }^{17}$ Available toolkit resources including those developed by the Commonwealth Fund in partnership with the Institute for Healthcare Improvement, ${ }^{18}$ the World Health Organization, ${ }^{19}$ and the Safer Healthcare Now! ${ }^{20}$ were examined in detail.

\section{Consultation With Experts}

The panel was composed of expert members from multiple disciplines and across several healthcare sectors, including PCPs, hospitalists, rehabilitation clinicians, nurses, researchers, pharmacists, academics, and hospital administrators. The aim was to create a discharge checklist to aid in transition planning based on best practices.

\section{Checklist-Development Process}

An improvement consultant (N.Z.) facilitated the process (Figure 1). The results of the literature review were circulated prior to the first meeting. The panel met 3 times in person over a period of 3 months, from January 2011 to March 2011. At the first meeting, the panel reviewed existing toolkits and evidence-based recommendations around best discharge practices. During the meeting, panel members were assigned to 1 of 6 groups (based on specialty area) and instructed to review toolkits and literature using a context-specific lens (primary care, home care, follow-up plans, communication to providers and caregivers, medication, and education). The goal of this exercise was to ensure that elements necessary for a successful discharge were viewed through the perspectives of interprofessional groups involved in the care of a patient. For example, PCPs in group 1 were asked to consider an ideal discharge from the perspective of primary care. Following the meeting, each group communicated via e-mail to generate a list of evidence-based items necessary for a safe discharge within the context of the group's assigned lens. Every group reached consensus on items specific to its context. A preliminary draft checklist was produced based on input from all groups. The checklist was created using recommended human-factors engineering concepts. ${ }^{21}$ The second meeting provided the opportunity for individual comments and feedback on the draft checklist. Three cycles of checklist revision followed by comments and feedback were conducted after the meeting, through e-mail exchange. A final meeting provided consensus of the panel on every element of the Safe Discharge Practices Checklist. 
TABLE 1. Checklist of Safe Discharge Practices for Hospital Patients

\begin{tabular}{|c|c|c|c|c|}
\hline & $\begin{array}{c}\text { Day of } \\
\text { Admission }\end{array}$ & $\begin{array}{l}\text { Subsequent } \\
\text { Hospital Days }\end{array}$ & $\begin{array}{l}\text { Discharge } \\
\text { Day }\end{array}$ & $\begin{array}{c}\text { Discharge } \\
\text { Day }+3\end{array}$ \\
\hline \multicolumn{5}{|l|}{ 1. Hospital } \\
\hline a. Assess patient to see if hospitalization is still required. & $\checkmark$ & $\checkmark$ & & \\
\hline a. Identify and/or confirm patient has an active PCP; alert care team if no PCP and/or begin PCP search. & $\downarrow$ & & & \\
\hline b. Contact PCP and notify of patient's admission, diagnosis, and predicted discharge date. & $\checkmark$ & & & \\
\hline c. Book postdischarge PCP follow-up appointment within 7-14 days of discharge (according to patientcaregiver availability and transportation needs). & & $\downarrow$ & & \\
\hline $\begin{array}{l}\text { b. Teach patient how to properly use discharge medications and how these relate to the medications patient was taking prior to admission. } \\
\text { c. Reconcile discharge medication order/prescription with BPMH and medications prescribed while in hospital. }\end{array}$ & i & $\downarrow$ & $\downarrow$ & \\
\hline \multicolumn{5}{|l|}{ 4. Follow-up } \\
\hline $\begin{array}{l}\text { a. Perform postdischarge follow-up phone call to patient (for patients with high LACE scores). During call, ask: } \\
\text { - Has patient received new meds (if any)? } \\
\text { - Has patient received home care? } \\
\text { - Remind patient of upcoming appointments. } \\
\text { - If necessary, schedule patient and caregiver to come back to facility for education and training. }\end{array}$ & & & & ل \\
\hline \multicolumn{5}{|l|}{ 5. Home care } \\
\hline \multicolumn{5}{|l|}{ a. Home-care agency shares information, where available, about patient's existing community services. } \\
\hline b. Engage home-care agencies (eg, interdisciplinary rounds). & $\downarrow$ & $\sqrt{ }$ & ل & \\
\hline c. If necessary, schedule postdischarge care. & & r & 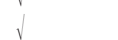 & \\
\hline 6. Communication & & & & \\
\hline \multicolumn{5}{|l|}{ a. Provide patient, community pharmacy, PCP, and formal caregiver (family, LTC, home-care agency) with copy of Discharge } \\
\hline \multicolumn{5}{|l|}{ Summary Plan/Note and the Medication Reconciliation Form, and contact information of attending hospital physician and inpatient unit. } \\
\hline \multicolumn{5}{|l|}{ 7. Patient education } \\
\hline a. Clinical team performs teach-back to patient. ${ }^{\dagger}$ & $\checkmark$ & $\sqrt{ }$ & l & \\
\hline b. Explain to patient how new medications relate to diagnosis. & $\downarrow$ & i & & \\
\hline c. Thoroughly explain discharge summary to patient (use teach-back if needed). & & & $\downarrow$ & \\
\hline d. Explain potential symptoms, what to expect while at home, and under what circumstances patient should visit ED. & & & ل & \\
\hline
\end{tabular}

NOTE: Abbreviations: BPMH, best possible medication history; ED, emergency department; LTC, long-term care, PCP, primary care physician.

*LACE index is a score calculated based on 4 factors: (L) length of hospital stay, (A) acuity on admission, (C) comorbidity, and (E) ED visits. A score of 10+ indicates high risk for readmission to hospital.

${ }^{T}$ Teach-back is the process of explaining information to patients and asking them to restate the information to assess accuracy. The instructor then repeats the process until the patient demonstrates correct recall and comprehension.

\section{RESULTS}

Evidence-based interventions pre-, post-, and bridging discharge were categorized into 7 domains: (1) indication for hospitalization, (2) primary care, (3) medication safety, (4) follow-up plans, (5) home-care referral, (6) communication with outpatient providers, and (7) patient education (Table 1). The panel reached $100 \%$ agreement on the recommended timeline to implement elements of the discharge checklist. Given the diverse interprofessional membership of the panel, it was felt that a daily reminder of tasks to be performed would provide the best format and have the highest likelihood of engaging team members in patient care coordination. It was also felt that daily interdisciplinary (ie, bullet) rounds would serve as the most appropriate venue to utilize the checklist tool.

The panel chose daily reminders to perform patient education around medications and clinical care for several reasons. Daily teaching provides an opportunity to assess information carried over and accurate understanding of treatment plans, as well as to review changes in care plans that may be evolving during a hospitalization. Although education starting on day 1 of admission may seem premature, we felt there was merit in addressing issues early. For example, patients admitted with heart failure can benefit from daily inpatient education around self-monitoring, diet, and lifestyle counseling. ${ }^{22}$

The literature review identified communication with PCPs as an important focus to prevent adverse events when patients transition from hospital to home. ${ }^{3}$ The expert panel agreed on admission notification, followup appointment scheduling, and transfer of a highquality discharge summary to the patient's PCP, such as one described by Maslove and colleagues. ${ }^{23}$ For example, summaries containing structured sections such as relevant inpatient provider contacts, diagnoses, course in hospital, results of investigations (including pending results), discharge instructions and follow-up, and medication reconciliation have been recommended to improve communication to outpatient providers. ${ }^{3}$ Use of validated scores such as the LACE index (a score calculated based on 4 factors: [L] length of hospital stay, [A] acuity on admission, [C] comorbidity, and [E] emergency department visits) to identify patients at high risk of readmission and 
targeting these individuals when arranging postdischarge follow-up is encouraged. ${ }^{24,25}$ Patients with high LACE scores $(\geq 10)$ would benefit from postdischarge follow-up phone calls within the first 3 days of returning home. In addition, high-risk patients may require an earlier follow-up appointment with the PCP, and the panel supports attempts to arrange follow-up within 7 days for at-risk individuals. For those without a PCP, it was recommended that a search should be initiated to assist the patient in obtaining a PCP.

Medication safety is a significant source of adverse events for patients returning home from the hospital. ${ }^{2,26-28}$ The discharge checklist provides prompts to reconcile medications on admission and discharge, in addition to daily patient education on proper use of medications. Formal medication reconciliation programs should be tailored to the individual hospital's own resources and requirements. ${ }^{29,30}$

Postdischarge care plays an important role in supporting the patient upon discharge and when part of a multifaceted discharge plan can result in decreased readmission rates and hospital utilization..$^{7,9,15,31}$ The panel incorporated these elements by recommending performing postdischarge phone calls, arranging outpatient follow-up if necessary, and coordinating home-care services through local agencies.

To facilitate transfer of information, patients, caregivers, outpatient providers, and community pharmacies are to be provided copies of a comprehensive discharge summary, medication reconciliation, and contact information of the inpatient team under the category of "Communication." Finally, as the teachback method is an effective tool to ensure patient understanding of their health issues, the panel recommended its use when educating patients on medication use, plan of care, and discharge instructions. ${ }^{32,33}$ Examples of scenarios where teach-back would be of benefit include changes in medications with a high risk of adverse events, such as warfarin or furosemide, to ensure patients understand the dosing, frequency, and monitoring required; and self-management skills (eg, daily weights and dietary changes) in patients with heart failure.

Finally, the panel noted that it was important to link the checklist items with relevant measures, audit, and feedback to determine associations between process and outcomes. The group avoided specific detailed recommendations to allow each institution to locally tailor appropriate process and outcome measures to assess fidelity of each component of the checklist.

\section{DISCUSSION}

A standardized, evidence-based discharge process is critical to safe transitions for the hospitalized patient. We have used a consensus process of stakeholders to develop a Checklist of Safe Discharge Practices for
Hospital Patients that details the steps of events that need to be completed for every day of a typical hospitalization. The day of discharge is often a confusing and chaotic time, with patients receiving an overwhelming volume of information on their last day in the hospital. We believe that discharge planning starts from the day of admission with daily patient education and a coordinated interdisciplinary team approach. The components of the discharge checklist should be completed throughout a patient's hospitalization to ensure a successful discharge and transmission of knowledge.

Discharge checklists have been described previously. Halasyamani and colleagues developed a checklist for elderly inpatients created through a process of literature and peer review followed by a panel discussion at the Society of Hospital Medicine Annual Meeting. ${ }^{34}$ The resultant tool described important data elements necessary for a successful discharge and which processes were most appropriate to facilitate the transfer of information. This differs significantly from our discharge checklist, which provides specific recommendations on methods and processes to effect a safe discharge in addition to an expected timeline of when to complete each step. Kripalani et al reviewed the literature for suggested methods of promoting effective transitions of care at discharge, and their results are consistent with those summarized in our discharge checklist. ${ }^{29}$ In contrast to both efforts, our group was multidisciplinary and had broad representation from the acute care, chronic care, home care, rehabilitation medicine, and long-term care sectors, thereby incorporating all possible aspects of the transition process. Coordinating discharge care requires significant teamwork; our tool extends beyond a checklist of tasks to be performed, and rather serves as a platform to facilitate interprofessional collaboration. In addition, this checklist was designed to integrate discharge planning into interprofessional care rounds occurring throughout a hospital admission. As well, our paper follows an explicit and defined consensus process. Finally, our proposed tool better follows a recommended checklist format. $^{21}$

The discharge process occurring during a patient's hospitalization is a complex, multifaceted care-coordination plan that must begin on the first day of admission. Often, transfer of important information and medication review take place only hours before a patient leaves the hospital, a suboptimal time for patient education. ${ }^{28,35}$ Just as standardized treatment protocols and care plans can improve outcomes, ${ }^{36} \mathrm{a}$ similar approach for discharge processes may facilitate safe transition from hospital to home. Our discharge checklist prompts hospital providers to initiate steps necessary for a successful discharge while allowing for local adaptation in how each element is performed. We suggest using the checklist during daily interprofessional team rounds to ensure each task is 
completed, if appropriate. Institutions may consider measuring process measures such as adherence and completion of checklist, audits of discharge summaries for completion and transmission rates to PCPs (by fax or through health record departments), and documentation of patient education or medication reconciliation. Example outcome measures, if feasible, include Care Transitions Measure (CTM) scores, patient satisfaction surveys, and readmission rates.

Several limitations of this study should be considered. First, current literature on safe discharge practices is limited by low study-design quality, with a paucity of randomized controlled trials. However, a recent systematic review found that bundled discharge interventions are likely to be most effective. ${ }^{10}$ Individual items of the checklist may not have had an extensive evidence base; however, some of these suggested elements (eg, contact home care) have clinical face validity. Second, the heterogeneity of interventions studied pose challenges in determining generalizable best practices without considering local factors. To mitigate this, we suggest adapting the checklist to local contexts and resource availability. Third, the checklist has not been tested. The next step of this project is to pilot checklist use through small-scale Plan-Do-Study-Act (PDSA) cycles followed by largescale implementation. We plan to collect baseline, process, and outcome measures before and after implementation of the checklist at multiple institutions to determine utility.

Standardization of discharge practices is critical to safe transitions and preventing avoidable admissions to hospital. Our discharge checklist is an expanded tool that provides explicit guidance for each day of hospitalization and can be adapted for any hospital admission to aid interdisciplinary efforts toward a successful discharge. Future studies to evaluate the checklist in improving care-transition processes are required to determine association with outcomes.

\section{Disclosures}

Nothing to report.

\section{References}

1. Forster AJ, Murff HJ, Peterson JF, Gandhi TK, Bates DW. The incidence and severity of adverse events affecting patients after discharge from the hospital. Ann Intern Med. 2003;138(3):161-167.

2. Roy CL, Poon EG, Karson AS, et al. Patient safety concerns arising from test results that return after hospital discharge. Ann Intern Med. 2005;143(2):121-128.

3. Kripalani S, LeFevre F, Phillips CO, Williams MV, Basaviah P, Baker DW. Deficits in communication and information transfer between hospital-based and primary care physicians: implications for patient safety and continuity of care. JAMA. 2007;297(8):831-841.

4. Poon EG, Gandhi TK, Sequist TD, Murff HJ, Karson AS, Bates DW. "I wish I had seen this test result earlier!": dissatisfaction with test result management systems in primary care. Arch Intern Med. 2004;164(20):2223-2228.

5. Coleman EA, Berenson RA. Lost in transition: challenges and opportunities for improving the quality of transitional care. Ann Intern Med. 2004;141(7):533-536.

6. Van Walraven C, Mamdani M, Fang J, Austin PC. Continuity of care and patient outcomes after hospital discharge. J Gen Intern Med. 2004;19(6):624-631.
7. Jack BW, Chetty VK, Anthony D, et al. A reengineered hospital discharge program to decrease rehospitalization: a randomized trial. Ann Intern Med. 2009;150(3):178-187.

8. Dedhia P, Kravet S, Bulger J, et al. A Quality improvement intervention to facilitate the transition of older adults from three hospitals back to their homes. J Am Geriatr Soc. 57(9):1540-1546.

9. Koehler BE, Richter KM, Youngblood L, et al. Reduction of 30-day postdischarge hospital readmission or emergency department (ED) visit rates in high-risk elderly medical patients through delivery of a targeted care bundle. J Hosp Med. 2009;4(4):211-218.

10. Hansen LO, Young RS, Hinami K, Leung A, Williams MV. Interventions to reduce 30-day rehospitalization: a systematic review. Ann Intern Med. 2011;155(8):520-528.

11. Centers for Medicare and Medicaid Services. Readmissions reduction program. Available at: http://cms.gov/Medicare/Medicare-Fee-forService-Payment/AcuteInpatientPPS/Readmissions-Reduction-Program. html.Accessed September 5, 2012.

12. Ontario Ministry of Health and Long-Term Care. The Excellent Care for All Act, 2010. Available at: http://health.gov.on.ca/en/public/ programs/ecfa/default.aspx/. Accessed February 28, 2013.

13. Ontario Ministry of Health and Long-Term Care; Baker GR, ed. Enhancing the Continuum of Care: Report of the Avoidable Hospitalization Advisory Panel, November 2011. Available at: http:// www.health.gov.on.ca/en/common/ministry/publications/reports/ baker_2011/baker_2011.pdf. Accessed August 8, 2012.

14. Naylor MD, Brooten DA, Campbell RL, Maislin G, McCauley KM, Schwartz JS. Transitional care of older adults hospitalized with heart failure: a randomized, controlled trial [published correction appears in J Am Geriatr Soc. 2004;52(7):1228]. J Am Geriatr Soc. 2004; 52(5):675-684.

15. Coleman EA, Parry C, Chalmers S, Min SJ. The care transitions intervention: results of a randomized controlled trial. Arch Intern Med. 2006;166(17):1822-1828.

16. Society of Hospital Medicine. Project BOOST: Better Outcomes by Optimizing Safe Transitions. Available at: http://www.hospitalmedicine.org/BOOST/. Accessed October 31, 2012.

17. The King's Fund; Ham C, Imison C, Jennings M. Avoiding Hospital Admissions: Lessons From Evidence and Experience. Available at: http://www.kingsfund.org.uk/publications/articles/avoiding-hospitaladmissions-lessons-evidence. Published October 28, 2010. Accessed September 4, 2012.

18. Nielsen GA, Rutherford P, Taylor J, eds. How-To Guide: Creating an Ideal Transition Home. Cambridge, MA: Institute for Healthcare Improvement; 2009. Available at: http://www.ihi.org or http://ah.cmsplus.com/files/IHI_How_to_Guide_Creating_an_Ideal_Transition_ Home.pdf. Accessed August 8, 2012.

19. World Health Organization. Action on Patient Safety-High 5s. Available at: http://www.who.int/patientsafety/implementation/solutions/high5s/en/index.html. Accessed October 29, 2012.

20. Safer Healthcare Now! Medication Reconciliation in Acute Care: Getting Started Kit. Available at: http://www.ismp-canada.org/download/ MedRec/Medrec_AC_English_GSK_V3.pdf. Accessed October 29, 2012.

21. US Agency for Healthcare Research and Quality. PSNet: Patientsafety primers, checklists. Available at: http://www.psnet.ahrq.gov/ primer.aspx?primerID=14. Accessed November 1, 2012.

22. Anderson C, Deepak BV, Amoateng-Adjepong Y, Zarich S. Benefits of comprehensive inpatient education and discharge planning combined with outpatient support in elderly patients with congestive heart failure. Congest Heart Fail. 2005;11(6):315-321.

23. Maslove DM, Leiter RE, Grimshaw J, et al. Electronic versus dictated hospital discharge summaries: a randomized controlled trial. J Gen Intern Med. 2009;24(9):995-1001.

24. Gruneir A, Dhalla IA, van Walraven C, et al. Unplanned readmissions after hospital discharge among patients identified as being at high risk for readmission using a validated predictive algorithm. Open Med. 2011;5(2):e104-e111.

25. Van Walraven C, Dhalla IA, Bell C, et al. Derivation and validation of an index to predict early death or unplanned readmission after discharge from hospital to the community. CMAJ. 2010;182(6):551557.

26. Resar R. Will, ideas, and execution: their role in reducing adverse medication events. J Pediatr. 2005;147(6):727-728.

27. Kucukarslan SN, Peters M, Mlynarek M, Nafziger DA. Pharmacists on rounding teams reduce preventable adverse drug events in hospital general medicine units. Arch Intern Med. 2003;163(17): 2014-2018.

28. Schnipper JL, Kirwin JL, Cotugno MC, et al. Role of pharmacist counseling in preventing adverse drug events after hospitalization. Arch Intern Med. 2006;166(5):565-571.

29. Kripalani S, Jackson AT, Schnipper JL, Coleman EA. Promoting effective transitions of care at hospital discharge: a review of key issues for hospitalists. J Hosp Med. 2007;2(5):314-323.

30. Fernandes O, Shojania KG. Medication reconciliation in the hospital. Healthc Q. 2012;15:42-49. 
31. Naylor M, Brooten D, Jones R, Lavizzo-Mourey R, Mezey M, Pauly $\mathrm{M}$. Comprehensive discharge planning for the hospitalized elderly: a randomized clinical trial. Ann Intern Med. 1994;120(12):9991006.

32. Schillinger D, Piette J, Grumbach K, et al. Closing the loop: physician communication with diabetic patients who have low health literacy. Arch Intern Med. 2003;163(1):83-90.

33. Cegala DJ, Marinelli T, Post D. The effects of patient communication skills training on compliance. Arch Fam Med. 2000;9(1):57-64.
34. Halasyamani L, Kripalani S, Coleman E, et al. Transition of care for hospitalized elderly patients-development of a discharge checklist for hospitalists. J Hosp Med. 2006;1(6):354-360.

35. McPhee SJ, Frank DH, Lewis C, Bush DE, Smith CR. Influence of a "discharge interview" on patient knowledge, compliance, and functional status after hospitalization. Med Care. 1983;21(8):755-767.

36. Pearson SD, Kleefield SF, Soukop JR, Cook EF, Lee TH. Critical pathways intervention to reduce length of hospital stay. Am J Med. 2001;110(3):175-180. 